\title{
Introduction to Wearable Technology and the Internet of Everything Minitrack
}

\author{
Jan Kietzmann \\ Simon Fraser University \\ jkietzma@sfu.ca
}

\author{
Leyland Pitt \\ Simon Fraser University \\ lpitt@sfu.ca
}

Constantine Katsikeas
Leeds University
csk@lubs.leeds.ac.uk
For this minitrack, we seek research papers that explore social, technological and organizational perspectives of emerging types of "Internets", including:

- The Internet of Things (IoT), as a computing concept that allows everyday physical objects to be connected to the "traditional" Internet, so that these are able to identify themselves to other devices and engage in seamless and automatic data exchange.

- The Internet of People (IoP) emerges when more and more embedded and wearable technologies (like Google Glass and Fitbit) extend people's roles from being mere users and observers of the Internet to becoming part of the Internet.

- The Internet of Everything (IoE) materializes when IoT and IoP converge, bringing together people, processes, data and things (objects) for a new, networked world of ever-expanding data streams.

We welcome empirical and theoretical submissions that address issues related to these Internets (particularly to IoP and the emerging IoE) in a variety of contexts, including but not necessarily limited to the following themes:

- Analysis and speculation of the successes, failures, winners, and losers

- Technologies, applications, security and organizational issues related to IoP and IoE

- Big data management (e.g., storing, accessing, analyzing, and reacting to IoP/ IoE data)

- Opportunities and challenges related to consumer behavior (e.g., privacy concerns) with respect to wearable and embedded technologies

- Key issues for innovators, developers, IT firms, and technology vendors 